Revista Destaques Acadêmicos, Lajeado, v. 9, n. 3, 2017. ISSN 2176-3070

DOI: http://dx.doi.org/10.22410/issn.2176-3070.v9i3a2017.1481

www.univates.br/revistas

\title{
RELATO DE EXPERIÊNCIA: PERCEPÇÃO ACERCA DO SIGNIFICADO DOS CORTES NO CORPO DO ADOLESCENTE ${ }^{1}$
}

\author{
Camila Eleutério Bussmann², Bernardete Pretto ${ }^{3}$
}

Resumo: Observa-se que, na atualidade, o cortar-se é uma das maneiras de marcar o corpo mais utilizada por jovens e adolescentes. Dessa forma, a presente pesquisa se propôs a discutir sobre o significado dos cortes no corpo do adolescente, a partir da experiência de estágio realizada em uma Estratégia de Saúde da Família, onde foi realizado o acompanhamento de uma adolescente que se cortava. O estudo caracterizase como de natureza qualitativa, através de uma abordagem exploratória e descritiva, em que alguns recortes das trocas ocorridas nos atendimentos serviram como analisadores para pensar sobre o tema proposto, articulando-o às teorias abordadas. O referencial teórico apresenta algumas considerações sobre a adolescência, sobre a importância das relações familiares e sociais, sobre o corpo em transformação nessa etapa da vida, assim como sobre os cortes e seus significados. Concluiu-se que os cortes no corpo dos adolescentes têm diversos significados, sendo que a desestrutura familiar da adolescente mencionada, a baixa autoestima, além de questões próprias da adolescência podem ser fatores que a levam a cortar-se.

Palavras-chave: Adolescência. Cortes no corpo. Subjetividade.

\section{INTRODUÇÃO}

A prática de estágio em Psicologia realizado em uma Estratégia de Saúde da Família - ESF localizada no interior do Rio Grande do Sul foi a base para o desenvolvimento deste artigo. O referido serviço atende a uma grande demanda de adolescentes, o que propiciou à pesquisadora experimentar o atendimento a esse público na clínica. Sempre se considerou desafiador atender adolescentes pela intensidade com que eles vivenciam suas emoções e

1 Artigo produzido na disciplina de Trabalho de Conclusão de Curso II, do Curso de Psicologia, da Univates.

2 Graduanda do Curso de Psicologia, Univates, camila-bussmann@hotmail.com

3 Me. Professora da Univates, bepretto@univates.br 
também por estarem constituindo sua identidade, fatores que ficam claramente evidenciados durante os atendimentos. Porém, em um desses momentos, deparei-me com uma adolescente que se cortava, esse aspecto aguçou minha curiosidade, principalmente sobre as motivações que a levam a se cortar sem conseguir encontrar outro meio de vasão dos seus impulsos que não o corte. Essa experiência motivou-me a abordar a questão do significado dos cortes no corpo do adolescente na pesquisa em questão. A prática de cortar-se pode ser também observada na contemporaneidade através de jogos como, por exemplo, o da baleia azul, que entre suas fases tem os cortes em forma de baleia no corpo chegando, em seu último desafio, a estimular o adolescente ao suicídio.

Diante das colocações acima, o presente estudo foi tecido em torno do problema "qual o significado dos cortes no corpo do adolescente?" e, pela metodologia adotada, trata-se de uma pesquisa de cunho qualitativo, pois pretende investigar aspectos subjetivos a respeito da temática escolhida. A escrita parte de uma análise exploratória em que a experiência de atendimento a uma adolescente serviu como base para pensar o tema do significado dos cortes no corpo nessa faixa etária. A escuta efetuada forneceu subsídio para várias reflexões, ou seja, foram feitos alguns recortes a partir do que chamou a atenção da pesquisadora nos atendimentos e eles foram utilizados como analisadores, a fim de permitir articular e ampliar questões teóricas. Nesse sentido, buscouse na literatura autores que trabalham com o tema da adolescência como Calligaris, Winnicott, Knobel, Cavalcanti, entre outros, além de contextualizarse o motivo da utilização do termo "cortes".

Inicialmente, o artigo apresenta uma breve contextualização do assunto da pesquisa, isto é, os cortes no corpo do adolescente. Após essa primeira parte, ele aborda os novos olhares acerca do assunto acima referido, o que perpassa fatores sociais e familiares. Por fim, este estudo ressalta, nas considerações finais da pesquisa, que os ferimentos têm diversos significados. Os que puderam ser percebidos durante os atendimentos foram colocados no decorrer desta escrita. Dessa forma, fica evidente o quanto o adolescente precisa ser visto em sua totalidade, dentro da cultura e do contexto em que está inserido.

Acredita-se que estas reflexões poderão auxiliar no aprimoramento da forma de cuidado em saúde mental dos adolescentes em sofrimento, já que estão voltadas a compreender o que leva esses sujeitos a cortarem o seu corpo e de quais formas podemos promover cuidados levando essa situação em consideração. Também, pretende-se contribuir para a compreensão dos diversos fatores envolvidos na motivação para os cortes, bem como para refletir sobre a clínica com adolescentes, que tem peculiaridades próprias desta faixa etária. Uma delas refere-se à vivência e expressão dos sentimentos, que é intensa e singular. Dessa forma, acaba sendo um desafio perceber o que está dentro do normal nessa etapa de constituição do sujeito e o que acaba desviando-se da normalidade, podendo assim ser patológico. 


\section{EXPERIENCIANDO NOVOS OLHARES ACERCA DOS CORTES NOS CORPOS DOS ADOLESCENTES}

A prática de estágio permite aos estudantes deparar-se com realidades variadas, o que possibilita aprendizagens singulares, além de novos olhares acerca dos diversos aspectos com os quais temos contato. $\mathrm{O}$ encontro, no ano de 2016, com uma adolescente de 15 anos remeteu-me a pensar sobre o sentido do corpo e do marcar-se ou machucar-se nessa faixa etária. Essa adolescente frequentemente comparecia as sessões mostrando os cortes que fazia em seus braços, em momentos nos quais sentia-se triste, frustrada ou até mesmo carente afetivamente. Considero importante colocar que essa adolescente já se cortava há algum tempo, quando a mãe então descobriu que isso acontecia e procurou ajuda no serviço de saúde.

Sobre essa experiência que enriqueceu minha formação, permitindo-me construir olhares e reflexões acerca do cuidado e da promoção de saúde, traz-se o conceito de experiência como

Uma experiência é mais do que cumprimento formal de um número de horas, de um lugar e espaço organizado para o aprender. A passagem do não-saber ao saber é um acontecimento, um momento intensivo, que não pode ser cronometrado, medido, regulado. Tal experiência não se constitui em um aprender qualquer, mas em um aprender que faz contágios, que compartilha gozos e alegrias, que envolve afectos potencializadores (MUNHOZ, 2012, p.18).

A partir desse olhar para a experiência como potencializadora e com base na experiência vivenciada, apresenta-se a seguir o que se pôde pensar acerca dos significados dos cortes no corpo da adolescente, buscando relacionar esses aspectos com a teoria consultada para o estudo.

\subsection{Frente aos cortes no corpo do adolescente, como podemos pensar nas relações que o perpassam?}

Ao tratarmos do significado dos cortes no corpo do adolescente, é necessário aprofundarmo-nos sobre essa fase do desenvolvimento humano. A adolescência pode ser entendida como uma fase do desenvolvimento, mas também como uma invenção social. Dessa forma, diversos fatores influenciam diretamente na constituição da personalidade desse sujeito em transição. Entre eles, estão as mudanças físicas, emocionais e sociais, como as transformações envolvendo a sexualidade e a descoberta do novo corpo, a intensidade e o extremismo das emoções, as novas relações e responsabilidades, bem como as transformações e conflitos que permeiam as relações familiares.

A partir dessas colocações, cabe refletirmos sobre o que diz Cavalcanti, ao expor que 
a adolescência, como conhecemos hoje, é fruto dos avanços científicos e transformações psicológicas, educacionais e socioculturais ocorridos a partir do século XIX. Até então, não era reconhecida como etapa de desenvolvimento nem como categoria social. $\mathrm{O}$ conceito está intimamente ligado à constituição da família nuclear moderna, ao prolongamento da idade escolar e à expansão das escolas para as diversas classes sociais. A Organização Mundial da Saúde (OMS) estabelece o período entre 10 e 19 anos; já para o Estatuto da Criança e do Adolescente brasileiro, a fase vai dos 12 aos 18 anos (CAVALCANTI, ([2007 E 2012]), p. 06).

Essa citação permite-nos pensar que a adolescência surgiu em um contexto histórico e que foi diretamente influenciado por fatores presentes na sociedade da época. Nesse sentido, também observa-se que a delimitação do tempo para ser adolescente é variável, provavelmente sofrendo também a influência de fatores sociais e culturais. Calligaris, referindo-se ao que é ser adolescente, registra:

ao longo de mais ou menos 12 anos, as crianças, por assim dizer, se integram em nossa cultura e, entre outras coisas, elas aprendem que há dois campos nos quais importa se destacar para chegar à felicidade e ao reconhecimento pela comunidade: as relações amorosas/ sexuais e o poder (ou melhor, a potência) no campo produtivo, financeiro e social. Em outras palavras, elas aprendem que há duas qualidades subjetivas que são cruciais para se fazer valer em nossa tribo: é necessário ser desejável e invejável (CALLIGARIS, 2000, p. 14 e 15).

Sendo assim, a adolescência pode ser definida como muito mais do que apenas uma faixa etária de transição, uma vez que, na contemporaneidade, é difícil especificar seu início e seu fim, pois percebe-se que está acontecendo um alongamento desse período. Sobre isso

pode-se dizer então que existe na atualidade um alongamento da adolescência, que começa hoje bem mais cedo do que outrora e que prolonga também bastante, no campo que se denominava antigamente de idade adulta. No que se refere à tradição brasileira, considerando a sua inscrição na cultura urbana, este alongamento me parece evidente (CARDOSO, 2011, p. 26).

Cabe aqui atentarmos para esse prolongamento da adolescência, pois quanto a ele existe um paradoxo ao perceber que

Parece-me importante também abordarmos a existência de um grande paradoxo que observamos na nossa cultura, pois ao mesmo tempo em que há um prolongamento da adolescência, uma maior dificuldade em sair da casa dos pais, em se inserir no mercado de 
trabalho, dificuldades, portanto em assumir um papel adulto, há concomitantemente uma pressão por maturidade e autonomia (CASTRO; STÜRMER, 2009, p. 163).

Entende-se, a partir disso, que não se pode definir de forma estanque o período da adolescência e que é nessa fase do desenvolvimento, entre a infância e a vida adulta, que o sujeito vai abandonando as características infantis e assumindo as adultas. Em relação a isso, é possível salientar que "o adolescente, do ponto de vista da psicanálise, é um sujeito em vias de transformação, imerso em um processo profundo de revisão de seu mundo interno e de suas heranças infantis, visando à adaptação ao novo corpo, às novas pulsões decorrentes da puberdade" (LEVY apud EIZIRIK; BASSOLS, 2013, p. 167).

Essa adaptação ao novo corpo e às novas experiências, pode levar o adolescente a portar-se de uma forma insegura ou até a agir de forma infantilizada. Uma das características da fala da jovem que acompanhei durante os atendimentos era a forma como colocava suas vivências, pois mesmo quando estava comentando algo que para ela gerava sofrimento ela falava sorrindo ou de maneira irônica sobre o assunto. Percebeu-se que essa era a forma encontrada pela adolescente para disfarçar sua insegurança e até mesmo seu nervosismo.

A oscilação de comportamentos, que variam da forma mais infantilizada, insegura, como mencionado acima, até formas mais agressivas e/ou prepotentes da adolescente, também levam a pensar no que podemos considerar como próprio da idade e o que poderia estar relacionado a alguma dificuldade maior e aos cortes que ela fazia em seu corpo. No decorrer dos atendimentos, várias questões relacionadas à família foram surgindo, mostrando que nesse caso havia fatores muito complicados permeando a relação da adolescente com seus pais.

Winnicott (apud Outeiral e Araújo, s/d), observa a importância do meio ambiente e dos pais para o desenvolvimento do adolescente ao afirmar que

muitas das dificuldades dos adolescentes, devidas às quais se procura ajuda profissional, DERIVAM do fracasso ambiental, e este fato por si só enfatiza a importância vital do ambiente e do meio familiar no caso da grande maioria de adolescentes que de fato alcançam amadurecimento adulto, mesmo se durante o processo deem dores de cabeça aos pais (WINNICOTT apud OUTEIRAL e ARAÚJO, s/d).

$\mathrm{Na}$ história de vida dos familiares dessa adolescente, pode-se perceber questões como histórico de depressão, uso de medicação, retardo mental, mãe com adoecimento relacionado à saúde mental, abandono tanto do pai da mãe da adolescente como também do pai desta jovem, irmão usuário de drogas, mãe muito violenta que não consegue ser referência para essa 
adolescente. Um ponto interessante mencionado pela adolescente foi o uso do termo "embolamento", como forma de expressar as questões da mãe que acabam influenciando nas relações das duas, pelo fato de a mãe depositar na jovem as suas questões pessoais, ou seja, como forma encontrada por ela para referir-se à mistura das vivências, desejos e sentimentos da mãe com os seus próprios. Esse fator incomodava a adolescente, pois essa citou que, quando seu pai retornou do lugar distante em que vive há anos, a adolescente não desejava conversar com ele, por estar entristecida com a ausência paterna. A mãe repreendeu-a, comentando que ela não teve a presença de seu pai e que se tivesse a oportunidade de vê-lo iria rapidamente até a companhia dele.

Porém, mesmo que o relacionamento com a mãe, segundo a adolescente, não fosse bom, foi através dela que essa jovem chegou ao atendimento, pois quem buscou o serviço de saúde foi a progenitora, por estar muito preocupada com os cortes no corpo da filha. Em vários momentos a mãe participou, indo até o serviço comentar as vezes em que ela havia se cortado, ou falar das questões que perpassavam o relacionamento das duas. Para pensarmos no papel dos pais e também na aliança terapêutica, parte-se da citação de Novick (2004, p. 286) quando afirma que "os pais desempenham um importante papel na vida e no tratamento dos adolescentes. Alianças terapêuticas têm de ser construídas entre os pais e o terapeuta, os adolescentes e os pais, o terapeuta e o adolescente, e entre os pais".

À vista disso, pode-se pensar nas diversas críticas da adolescente para com sua mãe, sendo que em um atendimento em que a mãe acompanhou a paciente, como havia sido solicitado, ficou evidente que na constituição familiar a mãe não é vista como alguém de referência, mas sim como igual. A adolescente, a todo o momento, ditava ordens a sua mãe acerca do que e como seriam feitas as coisas em casa, dizendo que faria quando quisesse e aos poucos. Por esse motivo brigavam muito, sendo que mãe acabava aumentando o tom de voz e a paciente retribuía tomando a mesma atitude.

Esse contexto leva-nos a pensar numa possível relação com os cortes que a adolescente faz em seu corpo. Poderíamos associar a fragilidade emocional e a dificuldade da jovem em conseguir lidar com as cobranças com essa busca de um lugar seu, de uma referência familiar que acaba sendo enfraquecida, além das pressões e mudanças desse período do desenvolvimento humano. Dessa forma, percebe-se que a menina corta-se como forma de lidar com seus sentimentos e emoções.

Para a psicanálise, os pais, na infância, são idealizados pela criança. $\mathrm{O}$ bebê inicialmente é parte da mãe e a mãe é aquela que consegue dar significado e sentido à criança. Com o tempo vai acontecendo a separação entre a mãe e o bebê, sendo que é a progenitora quem traz o pai à relação, que o apresenta para a criança. É o pai quem tem a função de mostrar para essa criança que a mãe não lhe pertence. Esse processo dá origem ao chamado triângulo edípico. 
Aberastuty (1991) ajuda-nos a pensar na importância da figura paterna para o adolescente, pois salienta que a entrada na adolescência, que é quando ocorre a maturação genital, obriga a criança a definir seu papel na procriação. A mesma autora também coloca que a totalidade de suas experiências com os pais e com o mundo externo, nesse momento, tende a orientar uma forma especial de desejar e, mais tarde, de conceber e de se relacionar com um filho.

Dessa forma, percebe-se o quanto a estrutura diferenciada dessa família, assim como a dificuldade emocional da mãe e a falta do pai, que pela distância em que mora pouco se relaciona com a adolescente, acabam gerando diversos conflitos no cotidiano familiar. Poder-se-ia pensar, então, que os cortes sejam uma forma de reação a essa relação familiar conflituosa, que durante os atendimentos ficou muito evidente.

Pensando em todos os aspectos apontados acima, pode-se intuir que a família tem papel essencial, pois, pelo fato de a adolescência tratar-se de uma fase com muitas mudanças, o adolescente necessita encontrar em sua família um suporte significativo para conseguir passar pela transição da infância para a vida adulta de forma saudável. De acordo com isso, Rassial (1997) coloca que:

o adolescente consiste menos em propor-lhe respostas do que aceitar tomar a sério suas questões, permitindo-lhe formulá-las em seu discurso, antes de precipitar-se em atos. Percebemos logo que nós mesmos partilhamos essas mesmas questões éticas ou ontológicas e que elas colocam em causa nossas escolhas antigas (RASSIAL, 1997, p. 88).

Cabe pensar então, na importância de a família entender esse processo da adolescência para conseguir ajudar o jovem a passar por esse período único e com características muito singulares que fazem parte do desenvolvimento humano. Além da questão das relações familiares, sabe-se que, à medida em que o sujeito entra na adolescência, começa a se manifestar a sexualidade, além de uma série de transformações biológicas, psicológicas e sociais. Esse novo corpo do adolescente, com todas as mudanças físicas, proporciona nova vivência: a sexualidade. Em relação a isso, Rezende (2011, p. 159) afirma que "é na adolescência que uma série de escolhas serão feitas, como a escolha profissional e a escolha de um parceiro, no despertar para a vida sexual. De alguma forma a adolescência é vista como a fase das alegrias, fase 'colorida' e repleta de esperança frente ao futuro".

Durante a vivência dos atendimentos da adolescente, percebeu-se a questão da descoberta da sexualidade e os envolvimentos amorosos, pois ela estava começando a se envolver sexualmente com um jovem. Além disso, percebeu-se a curiosidade em conhecer novas pessoas, pois ao brigar com $\mathrm{o}$ namorado, ela participou de uma festa na qual acabou relacionando-se com outra pessoa, porém por ter utilizado álcool não lembrava quem era essa pessoa. Essas situações podem ser consideradas como experiências comuns 
no tempo da adolescência e integram a cultura em que vivemos. Ao mesmo tempo, fazem pensar nos riscos associados às experiências com o uso de álcool e da sexualidade vivida de forma inconsequente ou impulsiva.

Em seus escritos sobre adolescência, Levisky (2004, p. 12) ressalta que

Sabe-se, hoje, que a adolescência é um fenômeno que surge na puberdade, com as manifestações da sexualidade genital e o surgimento da capacidade reprodutora ao lado de uma série de transformações biopsicossociais, que sofrem com as interferências da sociedade, da cultura, da história. Sua expressividade contém aspectos variáveis que dependem dos contextos histórico, econômico, religioso, ético, politico e geográfico, que compõem a cultura num dado lugar e numa dada época.

Pensando nisso, tem-se então situações envolvendo decepções e dificuldades nas relações afetivas que a adolescente teve dificuldades de elaborar e que podem ter contribuído com a necessidade de se cortar como, por exemplo, uma decepção amorosa quando não consegue ficar com o menino que gosta ou quando tem alguma discussão com seu namorado por algum motivo que, para ela, foi muito significativo naquele momento, mas que até chegar no atendimento havia perdido sua importância.

Além disso, também pensando na importância das relações que se estabelecem nesse período, percebeu-se que a adolescente demonstrou ciúme da melhor amiga, que deixa de ser o centro de todo esse afeto ao conversar com outra jovem. As brigas na escola acontecem, segundo a adolescente, por diversos motivos que para ela não são tão significativos quanto a própria briga. Isto é, mais importante do que o motivo pelo qual aconteceu a briga é o próprio conflito em si, pelas questões de rivalidade que estão envolvidas nessa relação.

Conforme Calligaris (2000), o adolescente, além de buscar formas para lidar com todas as mudanças que está passando, ainda precisa confrontar-se com a adolescência criada socialmente. Sendo assim, pode-se dizer que

nossos adolescentes amam, estudam, brigam, trabalham. Batalham com seus corpos, que se esticam e se transformam. Lidam com as dificuldades de crescer no quadro complicado da família moderna. Como se diz hoje, eles se procuram e eventualmente se acham. Mas, além disso, eles precisam lutar com a adolescência, que é uma criatura um pouco monstruosa, sustentada pela imaginação de todos, adolescentes e pais. Um mito, inventado no começo do século 20, que vingou sobretudo depois da Segunda Guerra Mundial (CALLIGARIS, 2000, p. 09).

Em relação a isso, pode-se salientar que o adolescente contemporâneo está perpassado por relações imediatistas em um tempo no qual tudo acontece rápida e simultaneamente. Assim, questões como mídia, tecnologia e moda 
fazem parte da vida desses jovens, estando presentes na família, na escola e no grupo de amizades.

Como exemplo da influência do social na vida e na forma de agir do adolescente, pode-se pensar nos jogos virtuais. Nos últimos tempos, novas formas de influência surgem, sendo uma delas o jogo conhecido como "Baleia Azul", que pode ser visto como um sintoma de aspectos presentes no contemporâneo como, por exemplo, as relações imediatistas, a estruturação familiar, entre outros. De acordo com jornal O Globo, pode-se dizer que o jogo da Baleia Azul

[...] consiste em uma série de 50 desafios diários, enviados à vítima por um "curador". Há desde tarefas simples como desenhar uma baleia azul numa folha de papel até outras muito mais mórbidas, como cortar os lábios ou furar a palma da mão diversas vezes. Em outra tarefa, o participante deve "desenhar" uma baleia azul em seu antebraço com uma lâmina. Como desafio final, o jogador deve se matar. (O Globo, 2017, texto digital).

O jogo acaba afetando com ênfase maior os adolescentes pelas características desse período do desenvolvimento humano que podem envolver o extremismo das emoções, a necessidade de transgredir normas, além da insegurança e baixa autoestima, entre outros. Ao pensar, então, no período da adolescência como repleto de mudanças corporais e emocionais que influenciam na formação da identidade, entende-se que ela é marcada por emoções vivenciadas de forma mais intensa e de maneira singular.

Em relação a essa questão, observou-se que o extremismo nas emoções era a característica central dos relatos da adolescente, pois ao nomear seus sentimentos utilizava os termos "eu amo" ou em contraponto a isso "eu odeio", muitas vezes até mesmo no decorrer do atendimento chegava a comentar que amava e após que odiava a mesma pessoa ou situação. Dessa forma, tornase possível perceber o quanto o adolescente apresenta o extremismo em suas emoções e o quanto elas modificam-se em pouco tempo. Por esse motivo, cada atendimento tinha um novo sentido em relação aos seus sentimentos e emoções.

Podemos, ainda, pensar na colocação de Knobel (1981), que afirma que, por a adolescência ser um período de contradições e de confusão emocional, ela pode ser confundida com um estado patológico.

Neste período flutua entre uma dependência e uma independência extremas, e só a maturidade lhe permitirá, mais tarde, aceitar ser independente dentro de um limite de necessária dependência. Mas, no começo, mover-se-á entre o impulso ao desprendimento e a defesa que impõe o temor à perda do conhecido. É um período de contradição, confuso, ambivalente, doloroso, caracterizado por 
fricções com o meio familiar e social. Este quadro é frequentemente confundido com crise e estados patológicos (KNOBEL, 1981, p. 13).

Seguindo essa linha de pensamento, é nessa etapa de transição da infância para a vida adulta denominada adolescência que acontecem mudanças, tanto físicas como psicológicas, tendo muito presente aspectos relacionados ao desejo de vida ou morte devido ao extremismo em que o adolescente vivencia suas emoções que estão muito afloradas. O sujeito precisa adaptar-se, além de aceitar e compreender sua nova condição, agora não mais como criança, mas sim como um jovem adulto. A pulsão de vida ou morte precisa ser compreendida, já que

no que concerne ao campo psicanalítico de idéias, só podemos presumir que se realiza uma fusão e amalgamação muito ampla, em proporções variáveis das duas classes de instintos, de modo que jamais temos de lidar com instintos de vida puros ou instintos de morte puros, mas apenas com misturas deles, em quantidades diferentes (FREUD, 1924. p. 181/182).

A partir dessas colocações, é possível pensar na pulsão de vida ou morte que esteve muito presente no decorrer dos atendimentos, sendo que, no início dos atendimentos, a jovem não comentava sobre desejo de morte ao se cortar. Porém, com o passar das situações, principalmente após uma briga muito grave com a mãe, a adolescente acabou cortando-se muito e, ao retornar ao atendimento, deixou evidente a vontade de morrer dizendo "Eu queria me cortar bem fundo, mas eu não consegui!". Como já foi mencionado, no início dos atendimentos o desejo de morte não era manifestado, apenas a necessidade de se cortar como forma de "anular" o sofrimento no momento de conflito. Porém, observou-se um agravamento dessa situação, levando a pensar que havia uma ideia de morte, quando a garota, como já mencionado, apresentou o desejo de se cortar de maneira mais profunda, chegando a demonstrar certa decepção por não conseguir aprofundar os cortes.

Todos esses fatores acima citados, que compõem o social e o tempo contemporâneo, em conjunto com as mudanças e as transformações advindas desse período de vida influenciam na constituição da identidade desse sujeito em desenvolvimento. Dessa forma, ao recebermos um adolescente na clínica, precisamos, além de entender as características ditas normais dessa etapa, também pensarmos no contexto que o perpassa, pois esses fatores constituem e influenciam o sujeito em atendimento clínico.

Enfim, pode-se pensar, a partir do que foi dito até aqui o quanto é significativo para compreendermos o comportamento adolescente considerarmos o contexto em que ele vive, suas relações, seu ambiente familiar. No atendimento clínico, esse pode ser um desafio para o profissional, à medida 
em que ele precisa conhecer o desenvolvimento psíquico e todos os aspectos que fazem parte deste tempo de vida, em sua complexidade.

\subsection{O corpo na adolescência e as marcas nesse corpo}

Sobre as mudanças advindas do período denominado adolescência, Knobel (1981) afirma que existem três lutos vivenciados pelo adolescente. O primeiro é o luto pela perda do corpo infantil, mudanças que são impostas biologicamente ao sujeito. O segundo é o luto pelo papel e a identidade infantil, pois precisa deixar de ser dependente para passar a assumir responsabilidades. O terceiro, o luto pelos pais da infância, que o adolescente tenta reter na sua personalidade, pois eles significam refúgio. Essa situação se agrava pelo comportamento dos pais que precisam aceitar seu envelhecimento, assim como o crescimento dos filhos.

Seguindo essa linha de pensamento, após abordar as mudanças advindas do período da adolescência em relação ao social e às relações, torna-se necessário pensarmos sobre os machucados causados pelos próprios adolescentes em seus corpos. Utiliza-se apenas o termo cortes, nesse trabalho, pois o entendemos como uma forma mais abrangente de fazer menção a esses ferimentos. ${ }^{4}$

As transformações físicas são características principais da adolescência. O corpo que cresce de forma desproporcional, os seios que aumentam - nas meninas -, os pelos que começam a crescer e, principalmente, aceitação desse novo corpo que está tomando formas adultas. A adolescência ocorre no período genital, conforme a teoria psicanalítica, que tem início na fase de maturação denominado puberdade. Em relação a isso, afirma-se que

a puberdade (do latim puber $=$ adulto) representa uma fase do ciclo vital que abrange um conjunto de transformações biológicas marcantes. Nessa fase do desenvolvimento humano, ocorre uma sequência de modificações neurológicas, hormonais e físicas que resultam na maturação sexual, permitindo ao organismo atingir sua forma e capacidade funcionais de adulto capacitado para a reprodução (FREITAS; HAGEL apud EIZIRIK; BASSOLS, 2013, p. 155).

No decorrer da adolescência ocorrem diversas mudanças orgânicas ocasionadas pelos hormônios presentes em nosso corpo, como nos meninos a testosterona e nas meninas o estrógeno e a progesterona. Em geral, acontece o

4 Neste trabalho optou-se por usar o termo "cortes" para falar de uma forma mais ampla dessa questão. Porém existem diversos termos utilizados pela literatura atual para fazer referência a os ferimentos realizados pelo adolescente em seu corpo, como: escarifações, automutilação, cutting, autolesivas 
crescimento acelerado, o que pode fazer o corpo tomar formas desproporcionais, causar acnes e desenvolvimento dos pelos pubianos. Porém, deve-se levar em consideração que o desenvolvimento é singular em cada sujeito, ou seja, não necessariamente acontecerá da mesma forma para todos. Sendo assim, "a mudança em meninos e meninas se dá em ritmos diferentes. Assim, em alguns momentos, há um grande descompasso entre ambos. O menino poderia dizer: "Se eu me atrasar, comece sem mim". Mas começar o quê?" (ESSLINGER \& KOVÁCS, 2006, p. 77).

Houzel ([2007 e 2012]) ressalta que as mudanças corporais nos adolescentes acontecem de forma acelerada e em pouco tempo, o que pode acarretar na necessidade por estar várias horas do dia em frente ao espelho, além de tornar-se mais estabanado.

É na adolescência que se ganham em média 20\% da estatura final e $50 \%$ do peso adulto - o que pode representar de 30 a $50 \mathrm{~cm}$ e cerca de $30 \mathrm{~kg}$ em três anos. E, enquanto espicham, os adolescentes adquirem duas características da idade: tornam-se estabanados e começam a passar horas na frente do espelho. A razão mais provável para ambas as coisas é que o cérebro se vê subitamente obrigado a ajustar seus mapas sensório-motores à nova realidade corporal, com muitos centímetros a mais de altura e novas proporções (HOUZEL, ([2007 E 2012]), p. 33).

Poder-se-ia pensar, a partir disso, que as diversas mudanças que ocorrem nessa etapa interfeririam também na autoestima dos adolescentes? No acompanhamento que aqui se apresenta, percebeu-se que a baixa autoestima também estava relacionada aos cortes no corpo da adolescente. Em alguns momentos, as falas da menina em relação a si mesma remeteram a pensar nisso como, por exemplo, quando ela diz: "É que eu não sou uma pessoa boa!", ou então quando afirma que se alguém a olha na escola, pensa que essa pessoa está imaginando coisas ruins sobre ela. Dessa forma, percebe-se que, quando passava por situações em que se sentia inferior, como nos momentos em que deixa de receber a atenção da mãe ou da melhor amiga, ela marcava seu corpo com cortes. Assim, é possível perceber que a adolescente tem arraigada uma percepção ruim de si mesma, achando-se muitas vezes incapaz ou até mesmo culpando-se pelas situações que acontecem a sua volta.

$\mathrm{O}$ adolescente precisa ser visto em sua integralidade, ou seja, como sujeito que está se desenvolvendo fisicamente como citado acima, mas que também está se constituindo emocionalmente. Dessa forma, as mudanças corporais, as novas relações e a transformação da maneira de perceber os pais, bem como a nova forma de compreender o mundo, os novos desafios, a vivência das emoções de maneira mais extrema e as novas experiências, constituem a identidade do adolescente. 
Em relação a isso, Levy apud Eizirik e Bassols (2013), diz que se pensará na identidade do adolescente como sendo constituída através de aspectos como o processo adaptativo que inclui a perda da identidade e do corpo infantil, assim como dos pais da infância, as mudanças biológicas da puberdade e as ansiedades ao se deparar com mudanças rápidas do corpo, ao mesmo tempo em que as psíquicas acontecem mais devagar, até que se possa estabelecer novamente um equilíbrio. Dessa forma, o adolescente poderá apresentar negação, estranheza, despersonalização, retraimento e momentos de insatisfação com a nova forma corporal e novas atribuições sociais. Nessa perspectiva, Castro e Stürmer (2009, p.166), sugerem que as patologias graves, em que existe risco de vida do adolescente, evidenciam falha no processo de simbolização e, dessa forma, as autoras ressaltam que "claro está que essas questões remetem às relações precoces com o objeto materno, bem como com as rupturas que se deram na construção desse aparelho psíquico, acarretando falhas no processo simbólico".

No que se refere ao desequilíbrio emocional e à dificuldade de simbolização, chamou a atenção a forma como a adolescente demonstrava que não estava bem. Quando estava em sofrimento, logo no início do atendimento, sinalizava suas angústias, mostrando os cortes nos braços. Isto é, sem conseguir expressar em palavras o sofrimento que estava passando, mostrava os cortes, que representavam para ela, segundo o que se conseguiu compreender, a expressão do sofrimento pelo qual passava. Assim, pode-se pensar que os cortes foram a maneira encontrada por essa adolescente para colocar em ato o sofrimento psíquico. A dificuldade de simbolizar é bem própria do período da adolescência, pois esse sujeito está constituindo sua identidade, sendo esse aspecto visível diversas vezes durante os atendimentos como, por exemplo, quando a adolescente após uma briga muito severa com a mãe, por ela ter descoberto um conflito da adolescente na escola, acaba se cortando muito profundamente, chegando a ser levada ao hospital para receber atendimento. Após esse fato, ao retornar ao atendimento mostrou os braços, relatou o sofrimento durante o conflito familiar e salientou que nesses momentos a única coisa que a acalma e ameniza a dor, são os cortes.

Sobre a relação entre a dificuldade de simbolizar e os cortes, podese pensar no que diz Nasio (1993), que afirma que a automutilação pode ser pensada como um sintoma que se manifesta em forma de dor e alívio, um sofrimento para o eu e um alívio para o inconsciente. Em relação a isso, Outeiral (1982), coloca que o adolescente é perpassado por diversas mudanças, as quais trazem consigo turbilhões de emoções, que, de maneira gradativa, ele vai aprendendo a gerenciar. Portanto,

as modificações corporais da adolescência dão origem a um período evolutivo com características e conflitos muito específicos, nos quais o corpo desempenha importante papel, como base das angústias do indivíduo em crescimento. Todas estas modificações significam uma 
inevitável incursão no desconhecido. O adolescente, ao deparar-se com um corpo desconhecido, diferente daquele idealizado, está de luto pelo corpo infantil que perde, pelos pais da sua infância, pela identidade infantil, pelas fantasias de bissexualidade, pela endogamia e pelo corpo adolescente que desejaria ter (OUTEIRAL, 1982, p. 23).

Assim, fica evidente a importância de se perceber o adolescente em sua totalidade, pois ele está passando por diversas transformações e mudanças como já citado anteriormente. Entre essas mudanças estão as corporais, que acontecem muito rapidamente. Dessa forma, podemos pensar nos cortes no corpo do adolescente como uma forma do sujeito de se apropriar desse novo corpo, que está se constituindo, moldando-se. As modificações corporais deixam marcas também no psiquismo do adolescente e, sobre isso, argumentase que

quando o corpo do adolescente sofre modificações, que consequência advêm em seu psiquismo? Aí se abre um complexo jogo identificatório, no qual o olhar, tal como no estádio de formação da imago especular, é fundamental. O sujeito é intimado a realizar um reordenamento profundo no seu eu, um reordenamento do seu imaginário (CASTRO E STÜRMER, 2009, p. 157).

Possivelmente, mudanças corporais, emocionais e sociais, além do contexto escolar e familiar influenciam nas demandas adolescentes vivenciadas na clínica psicológica. A partir desse paradigma, pode-se ressaltar que

ao analisarmos melhor a situação, descobrimos que o distúrbio do adolescente quase que, invariavelmente, tem seus percursores em problemas graves pré-escolares e da latência, no contexto da patologia parental e de áreas de disfunção familiar, muito importantes (NOVICK, 2004, p. 285).

Dessa maneira, o adolescente marca seu corpo como forma de apropriação, buscando dar a esse novo corpo características, contornos e marcas singulares. Sobre isso, é possível denotar que

nesse momento, detemo-nos em um aspecto que tem atraído a atenção, que é a realização, cada vez mais frequente, da utilização da pele em tatuagens, piercings, body art, chegando à utilização de artefatos sob a pele. O que estaria significando esta busca intensa de tatuagens, colocação de piercings nos olhos, língua, genitais? (CASTRO; STÜRMER, 2009, p. 167).

Porém, algumas vezes, essas marcas no corpo agravam-se e tornam-se patológicas. Nesse sentido, os mesmos autores, falam que se 
observamos com maior ênfase a incidência das patologias das condutas agidas, como anorexia, bulimia seguida de vômitos, práticas toxicomaníacas, atos suicidas e, mais recentemente, automutilações. Essas patologias exigem de nós alterações em relação ao enquadre e à conceitualização teórica, fazendo com que haja um deslocamento, em que passa a ser necessário nos centrarmos nas verdadeiras relações de objetos, bem como nas relações narcísicas de objeto, em vez da análise dos conflitos ligados à repressão, abordagem esta, típica, no campo das neuroses (CASTRO; STÜRMER, 2009, p. 166).

Em relação aos cortes, notou-se que, ao questionar a adolescente sobre o que sentia no momento em que se cortava, ela respondeu: "não sinto nada", ou seja, cortava-se como forma de anular a dor psicológica, e assim dar vasão aos sofrimentos, pois esse foi o modo encontrado por ela para deixar de sentir a dor emocional ou até mesmo a maneira de lidar com as situações acima colocadas, tais como os conflitos familiares, questões típicas da adolescência, baixa autoestima, fragilidade da adolescente.

Pensando no até agora dito é importante refletir sobre a afirmação de Castro e Stürmer (2009, p.167), que relatam que em sua prática clínica é comum ouvir dos pacientes frases como "Eu só me acalmo quando me corto", denotando que por meio da dor sentida na pele, há uma tentativa de encontrar um continente, uma representação diante de uma angústia impossível de ser colocada em palavras.

Em síntese, percebe-se o quanto as vivências da clínica dos autores citados no decorrer dessa escrita assemelham-se ao olhar construído durante o atendimento da adolescente pela pesquisadora, pois eles também entendem o corte como uma forma de suportar a dor e a angústia emocional.

\section{OLHARES POSSÍVEIS...}

Com a finalidade de responder ao problema que esta pesquisa se propôs a aprofundar, busquei um referencial teórico que enriqueceu esta escrita ao embasar os olhares da pesquisadora sobre os significados dos cortes no corpo do adolescente. No início da pesquisa, estive muito perpassada pelo tema abordado por ela, questionando-me sobre o significado desses cortes, sobre aspectos que levam a adolescente a se cortar. Porém, ao longo do trabalho, verifiquei que o extremismo nas emoções, aspecto característico da fase do desenvolvimento humano denominada adolescência, assim como uma diversidade de fatores podem propiciar a ocorrência dos cortes. Cortar-se é a maneira encontrada pela jovem para dar vasão aos sentimentos e angústias, ou seja, ela utiliza-se dos cortes como forma de anular a dor psíquica.

Tendo como objetivo geral entender o significado dos cortes no corpo do adolescente pude, através de minha experiência, constatar que a família tem papel fundamental pois o adolescente está passando por diversas mudanças 
físicas, psicológicas e sociais e precisa sentir que tem segurança junto à família. O jovem tem a necessidade de perceber o núcleo familiar como referência, como porto seguro, para poder vivenciar todas as situações novas presentes nessa fase de sua vida. Contudo, a estrutura familiar diferenciada da adolescente mencionada, a falta de diálogo e de apoio, além do desequilíbrio emocional da mãe, podem ser fatores que levam-na a cortar-se.

Percebe-se que as diversas mudanças físicas e psicológicas pelas quais a adolescente está passando, além da necessidade de lidar com esse novo corpo que precisa ser marcado, ser moldado, para se tornar um território conhecido e com características próprias daquele jovem, podem acarretar na diminuição da autoestima. Pode-se intuir, então, que a baixa autoestima poderia ser um dos motivadores dos cortes no corpo.

Coloca-se que os atendimentos não continuaram, pois a adolescente não aceitou mais frequentar o serviço. Acredita-se que por influência da mãe a qual também necessitava de atendimentos, porém não desejava trabalhar suas questões. No decorrer do processo terapêutico não se se percebeu diminuição dos cortes, pois foi necessário reiniciar os atendimentos inúmeras vezes por desistência da adolescente, sendo que cada vez que essa desistia, os profissionais do serviço realizavam visitas domiciliares para que essa retornasse aos atendimentos.

Ressalto a necessidade de se levar em consideração que, por tratar-se de um relato de experiência, essa escrita tem o olhar voltado para a maneira subjetiva da pesquisadora que vivenciou os atendimentos da adolescente, sendo que é importante pensar que cada sujeito experiencia as situações de maneira única e singular. Assim, outros trabalhos poderão encontrar conclusões diferenciadas da apresentada no atual estudo.

A partir do que foi exposto, fica evidente a necessidade de realizar novos estudos que visem enriquecer e aprofundar ainda mais os conhecimentos acerca da adolescência, que possam auxiliar os profissionais da Psicologia a contribuírem ainda mais para as práticas de cuidado voltadas a essa etapa do desenvolvimento humano. Por fim, é possível afirmar que os cortes no corpo dos adolescentes têm diversos significados, sendo que aqueles que puderam ser percebidos durante os atendimentos foram colocados nesta escrita. Dessa forma, fica evidente o quanto o adolescente precisa ser visto em sua totalidade, dentro da cultura e do contexto em que está inserido.

\section{REFERÊNCIAS}

ABERASTURY, Arminda; SALAS, Eduardo J. A paternidade: um enfoque psicanalítico. Porto Alegre: Artes Médicas, 1991

CALLIGARIS, Contardo. A adolescência. São Paulo: Publifolha, 2000. 
CARDOSO, Marta Rezende. Adolescentes. 2. ed. São Paulo: Editora Escuta, 2011.

CASTRO, Maria da graça Kern; STÜRMER, Anie. Crianças e adolescentes em psicoterapia: a abordagem psicanalítica. Porto Alegre: Artmed, 2009.

CAVALCANTI, Laura Battaglia. Retratos da adolescência. Revista Mente e Cérebro. Ed. esp. São Paulo, v. 1, p. 06, 2007 e 2012.

CHEMIN, Beatris Francisca. Manual da Univates para trabalhos acadêmicos: Planejamento, elaboração e apresentação. 3. ed. Lajeado: editora Univates, 2015.

ESSLINGER, Ingrid; KOVÁCS, Maria Júlia. Adolescência: Vida ou morte?. São Paulo: Ática, 2006.

FREITAS, Lúcia Helena; HAGEL, Lilian Day. A puberdade. In: EIZIRIK, Cláudio Laks; BASSOLS, Ana Margareth Siqueira. O ciclo da vida humana: uma perspectiva psicodinâmica. 2. Ed. Porto Alegre: Artmed, 2013.

FREUD, Sigmund. O problema econômico do masoquismo. In: Obras Completas, Rio de Janeiro: Imago, 1996. (publicado originalmente em 1924).

HOUZEL, Suzana Herculano. Novas equações cerebrais. Revista Mente e Cérebro. Ed. esp. São Paulo, v. 1, p. 33, 2007 e 2012.

KNOBEL, M.; ABERASTURY, M. Adolescência normal. $5^{\mathrm{a}}$ ed. Porto Alegre: Artes Médicas, 1981.

LEVISKY, David L. Adolescência: Psicanálise e história. In: GRAÑA, Roberto, B; PIVA, Angela, B.S. A atualidade da psicanálise de adolescentes: formas do mal-estar na juventude contemporânea. São Paulo: casa do psicólogo, 2004.

LEVY, Ruggero. O adolescente. In: EIZIRIK, Cláudio Laks; BASSOLS, Ana Margareth Siqueira. O ciclo da vida humana: uma perspectiva psicodinâmica. 2. ed. Porto Alegre: Artmed, 2013.

MUNHOZ, Angélica Vier. Diálogos na Pedagogia. Ed: Univates, 2012.

NOVICK, Jack. A aliança terapêutica no trabalho com adolescentes. In: GRAÑA, Roberto, B; PIVA, Angela, B,S. A atualidade da psicanálise de adolescentes: formas do mal-estar na juventude contemporânea. São Paulo: Casa do Psicólogo, 2004.

NASIO, Juan D. O conceito de castração. Lições sobre os sete conceitos cruciais da psicanálise. Rio de Janeiro: Jorge Zahar, 1997.

O QUE se sabe até agora sobre o jogo "Baleia Azul”. O Globo, 20 abr. 2017. Disponível em: <https:/ / oglobo.globo.com/sociedade/o-que-se-sabe-ate-agora-sobre-jogo-dabaleia-azul-21236180>. Acesso em: 08 jun. 2017. 
OUTEIRAL, José O. Infância e adolescência: psicologia do desenvolvimento, psicopatologia e tratamento. Porto Alegre: Artes Médicas, 1982.

OUTEIRAL, José Ottoni; ARAÚJO, Sandra Ma Baccara. Winnicott e a adolescência. Docslide. Disponível em: <http:/ / docslide.com.br/documents/winnicott-e-aadolescencia-texto-sampa.html>. Acesso em: 08 jun. 2017.

RASSIAL, Jean Jaques. A passagem adolescente: da família ao laço social. Porto Alegre: Artes e Oficio, 1997.

REZENDE, Marta. C. (org.). Adolescentes. São Paulo: Editora Escuta, 2011. 